\title{
Chestnut peels and wheat bran at different water level influence the physical properties of pan bread
}

\author{
Marcello Alinovi ${ }^{1} \cdot$ Massimiliano Rinaldi $^{1} \cdot$ Maria Paciulli $^{1}$ [D $\cdot$ Paola Littardi ${ }^{1} \cdot$ Emma Chiavaro $^{1}$
}

Received: 9 August 2021 / Revised: 29 December 2021 / Accepted: 2 January 2022 / Published online: 13 January 2022

(c) The Author(s) 2022

\begin{abstract}
In breadmaking, dietary fibres are used to improve the nutritional quality of the final products; on the other hand, they may affect the physical and sensory properties. This work aimed to the evaluate, on pan breads, the effect of substituting $3 \mathrm{~g}$ of wheat flour with an equivalent amount of fibre rich ingredients: chestnut peels (CP) or wheat bran (WB), in comparison to a traditional wheat bread formulation (C). The effect of four levels of added water (54,60, 66, $71 \mathrm{~g} / 100$ of flour) was also tested. The fibre content of CP (33\%) and WB (42\%) affected their water binding capacity and, consequently, the quality of the final loaves, according to the different water addition levels. In bread crumb, water content and water activity increased proportionally to the water addition levels, being instead in the crust also affected by the presence of fibres: lower water retention capacity was observed for $\mathrm{CP}$, in comparison to $\mathrm{WB}$ and $\mathrm{C}$. The loaf volume resulted higher for $\mathrm{C}$ in comparison to $\mathrm{WB}$ and $\mathrm{CP}$, in relation to the larger dimensions of the crumb pores, probably due to the interfering effect of fibres during the development of the gluten network. Crumb hardness resulted higher for $\mathrm{C}$ at low water addition levels, being instead higher for $\mathrm{CP}$ at high water addition levels. $\mathrm{CP}$ showed a darker and redder colour, than both WB and $\mathrm{C}$ bread, for the presence of the brown pigments carried by chestnut peels. PCA analysis confirmed that more water is required for both the fibre-enriched breads to show characteristics similar to the control loaves.
\end{abstract}

Keywords Chestnut peels $\cdot$ Wheat bran $\cdot$ Dietary fibre $\cdot$ Bread $\cdot$ Colour $\cdot$ Texture $\cdot$ Crumb

\section{Introduction}

The term "dietary fibre" indicates carbohydrate polymers with three or more monomeric units, which are neither digested nor absorbed in the human small intestine [1]. Dietary fibres are currently the subject of numerous studies aimed at investigating their positive effects, linked to both health and organoleptic aspects. Indeed, the fibre intake seems to have positive effects on health such as improvement of intestinal function, prebiotic activity, reduction of blood cholesterol levels, and attenuation of post-prandial blood glucose and insulin levels [2]. According to Reg. (EC) No. $1924 / 2006$ [3], it is possible to use the claim "source of fibre" when the product contains at least $3 \mathrm{~g}$ of fibre per $100 \mathrm{~g}$ or at least $1.5 \mathrm{~g}$ of fibre per $100 \mathrm{kcal}$. Dietary fibres are

Maria Paciulli

maria.paciulli@unipr.it

1 Dipartimento di Scienze degli Alimenti e del Farmaco, Università di Parma, Parco Area delle Scienze 27/A, 43124 Parma, Italy interesting not only for their nutritional properties, but also for their functional and technological properties $[4,5]$. It is well known that the incorporation of fibre, extracted from different sources, into food such as meat products, breakfast cereals, and bakery goods can change its structure, texture, stability, and rheological properties [6-8].

When added to bread formulations, fibres could affect microstructure, texture, and shelf life of the final products [9]. Wheat bran is the most largely considered fibre for the production of "whole" breads [10]. However, with the increasing demand for sustainable food productions, food by-products such as the ones derived from legumes or from vegetable processing, rich in fibre and/or in other components (vitamins, minerals, antioxidants, etc.) are being used alternatively or coupled with wheat bran. In the last years, several authors evaluated the applicability of different vegetable by-products (e.g., green coffee parchment, cocoa bean shells, and legume hulls) rich in dietary fibres and other bioactive compounds to produce bread formulations [11-14].

In this view, the main by-product of the chestnut industry is the peels (composed by pericarp and integuments). 
Chestnut peels represent about $6-10 \%$ of the fruit weight [15] and they contain about $30 \%$ of fibre, consisting mainly of lignin, cellulose, and hemicellulose, as well as being an important source of phenolic molecules (tannins and ellagitannins) with antioxidant activity and other bioactive compounds [16]. These properties make chestnut peels useful both as functional ingredients as well as a source for extraction of specific compounds.

The functional properties of chestnut peels have been previously studied for the enrichment of foods such as cookies [17] and sausages [18], but there are not scientific data about the use of chestnut peels in breadmaking. In addition to the food functionalization, the use of chestnut peels can contribute to the reduction of food waste and the further enhancement of the chestnut supply chain.

From a technological point of view, it is well known that the addition of fibre-containing ingredients to a bread formulation can modify the optimum water absorption level of the system during the kneading step $[19,20]$ During breadmaking, if the level of added water is insufficient for the hydration of all dough ingredients, the gluten does not become fully hydrated and its elastic nature does not become fully developed. Conversely, an excessive level of free water results in an increased extensibility and stickiness of the dough. Eventually, the amount of water can modify the microstructure, texture, volume, and even colour of the final bread loaves [21, 22].

In this context, the present work aimed to compare the technological performance of chestnut peels and wheat bran supplementation for bread making, in comparison to a standard bread without added fibres. The physicochemical characteristics of the final loaves were analysed, by exploring also the influence of different amounts of water added to the dough.

\section{Materials and methods}

\section{Materials, bread formulation, and breadmaking}

Chestnut peels were obtained from "I briganti di Cerreto", a local community cooperative (Reggio Emilia, Italy), and were collected as by-products of the production of chestnut flour. The chestnut flour was obtained with a traditional method from fruits dried at constant temperature $\left(40{ }^{\circ} \mathrm{C}\right)$ for 40 days in an old-fashioned drying kiln called "metato". Metato is a structure of around 10-20 $\mathrm{m}^{2}$ composed by two levels: chestnuts are positioned in the upper level (as a layer of 40-80 cm thickness) and are dried with the aid of heat generated from the flame-free combustion of chestnut tree wood, that takes place in the lower level. Chestnut peels were ground in a blender Osterizer 890-49H (Oster, USA) for $2 \mathrm{~min}$ at the maximum speed.
Wheat bran was kindly provided by Molino Bongiovanni S.r.l. (Villanova Mondovì, Italy).

The granulometry of both alternative plant raw materials was determined by laser diffraction method (details hereafter).

Soft wheat multipurpose flour type " 0 " (dough alveograph energy W: 250 ; fats: $1.6 \mathrm{~g} / 100 \mathrm{~g}$; carbohydrates: $73 \mathrm{~g} / 100 \mathrm{~g}$; fibres: $1.2 \mathrm{~g} / 100 \mathrm{~g}$; proteins: $12 \mathrm{~g} / 100 \mathrm{~g}$; ashes: $0.05 \mathrm{~g} / 100 \mathrm{~g}$ ), as legally defined by the Italian Government Official Bulletin [23], was purchased from a local market as a single production lot.

The sampling scheme was " $3 \times 4$ " in term of flour type (C, CP, and WP) and levels of added water $(54,60,66$, and $71 \mathrm{~g} / 100 \mathrm{~g}$ flour). Each bread type was produced in two or three production batches, resulting in a total amount of 24 $(3 \times 4 \times 2)$ or $36(3 \times 4 \times 3)$ bread loaves.

Pan bread samples were as follows: C, control (100 g/100 g of soft wheat flour); WB, bread prepared by substituting in the control recipe $3 \mathrm{~g}$ of soft wheat flour with $3 \mathrm{~g}$ of wheat bran; $\mathrm{CP}$, bread prepared by substituting in the control recipe $3 \mathrm{~g}$ of soft wheat flour with $3 \mathrm{~g}$ of chestnut peel.

Pan bread samples were produced using the following formulation, expressed on a flour basis: soft wheat flour (without and with fibre supplementation) $(100 \mathrm{~g})$, water $(54,60,66$, and $71 \mathrm{~g})$, yeast $(1.7 \mathrm{~g})$, sunflower oil $(6.5 \mathrm{~g})$, and salt $(2.0 \mathrm{~g})$. To simplify, these quantities are here reported on $100 \mathrm{~g}$ of soft wheat flour; the real flour dose used for one loaf of bread was $450 \mathrm{~g}$ with relative proportions of the other ingredients.

A domestic bread maker machine (Moulinex, Groupe Seb Italia S.p.A., Milano, Italy) was used for bread making, with the following program: stirring + kneading, + rising, $136 \mathrm{~min}$; baking, $53 \mathrm{~min}$ at $210^{\circ} \mathrm{C}$. The breads were then equilibrated at $25{ }^{\circ} \mathrm{C}$ in a temperature-controlled chamber (ISCO 9000, Milan, Italy) for $2 \mathrm{~h}$ and analysed the same day of bread making.

The ratios of chestnut peels or wheat bran/soft wheat flour and the used water levels were optimized in terms of sensory characteristics, by performing preliminary tests, to obtain loaves with acceptable physical and sensory properties. The trials were conducted during a master thesis in Food Science and Technology at the University of Parma, Italy (data not published) [24].

\section{Physico-chemical analyses on chestnut peels and wheat bran}

The total fibre content of chestnut peels and wheat bran was measured according to the AOAC Method 2009.01 [25]. The results are expressed as percentage on dry weight (dw). 
Water-binding capacity (WBC) of chestnut peels and wheat bran was determined as described by Paciulli et al. [26].

Particle size of both chestnut peels and wheat bran was measured by means of a laser diffraction particle-size analyzer (Beckman Coulter Inc., USA) with the following parameters: 350 mbar vacuum, obscuration $8 \%$, and run length of $19 \mathrm{~s}$. All the analyses were performed in triplicate.

\section{Analyses on bread}

\section{Moisture content and water activity}

Moisture contents of breads were measured according to AOAC 925.09 [27], in triplicate, on crust and crumb.

The water activity $\left(a_{\mathrm{w}}\right)$ of bread crumb and crust (crust thickness: $1.5 \pm 0.2 \mathrm{~mm}$ ) was determined in triplicate at $25.0 \pm 0.2{ }^{\circ} \mathrm{C}$ using an electronic dew-point water activity meter Aqualab Series 4 model TE (Decagon Devices, Pullman, Washington, USA) calibrated with saturated salt solutions and deionized water in the $a_{\mathrm{w}}$ range of 0.846-1.000.

\section{Specific volume and crumb grain analyses}

Specific volume of bread types was determined for each loaf, according to the standard rapeseed displacement methodology [28], and it was expressed as the volume/weight ratio of cooked bread (mL/g).

Crumb porosity was evaluated on two central slices (20 mm thickness) from each loaf. Images were acquired with a Scanjet 8200 flatbed scanner (Hewlett-Packard, Palo Alto, CA, USA), with a resolution of 600 dots per inch (dpi) and converted from true colour to $256-$ level grey scale. Analyses were performed on $40 \times 40 \mathrm{~mm}$ squares taken from the center of the images after their calibration, standardization, and optimization by means of appropriate filters carried out with Image-Pro Plus 4.5 software (Media Cybernetics Inc., USA), as previously reported by Rinaldi et al. [29]. The same software was employed for data processing to quantify the pores present in five pre-selected dimensional classes based on their area (class $1,0.001-0.005 \mathrm{~mm}^{2}$; class 2, 0.005-0.008 $\mathrm{mm}^{2}$; class 3, 0.008-0.010 $\mathrm{mm}^{2}$; class 4, $0.010-1.000 \mathrm{~mm}^{2}$; class $5,>1.000 \mathrm{~mm}^{2}$ ) to obtain the number of pores of each class and the area occupied by each class (expressed as percentage of the total number of pores). Pores' density (pores/ $\mathrm{mm}^{2}$ ) was also measured. Each analysis was performed in triplicate.

\section{Textural analyses}

Texture analysis was performed on crust and crumb using a TA.XT2 Texture Analyzer equipped with a $25 \mathrm{~kg}$ load cell (Stable Micro Systems, Godalming, UK). Crust hardness was measured by means of a puncture test using a $3 \mathrm{~mm}$-diameter stainless steel probe and a test speed of $2 \mathrm{~mm} / \mathrm{s}$. Maximum peak force $(N)$ was measured from the penetration curve and taken as crust hardness. Measurements were performed on five pre-selected points of the crust of three loaves per samples.

Crumb evaluation was carried out on ten cube of $20 \mathrm{~mm}$ side obtained from two central slices of three loaves per samples, by cutting with an electrical knife (Moulinex) and then measured with a calliper to ensure repeatability. A Texture Profile Analysis (TPA) test was performed on the crumb cubes with a $35 \mathrm{~mm}$-diameter cylindrical aluminium probe by means of a double compression with a speed of $1 \mathrm{~mm} / \mathrm{s}$ up to the $50 \%$ of the original sample height. The textural parameters considered were hardness (maximum peak force of the first compression cycle, $N$ ), cohesiveness (ratio of positive force area during the second compression to that during the first compression area, dimensionless), resilience (area during the withdrawal of the first compression cycle, divided by the area of the first compression, dimensionless), and chewiness (hardness $\mathrm{x}$ cohesiveness x springiness, $N$ ).

\section{Colorimetric analyses}

Colour was determined separately on crust and crumb using a Minolta Colorimeter (CM 2600d, Konica Minolta Sensing, Osaka, Japan) equipped with a standard illuminant D65 and a Spectramagic 3.6 software for data analysis. The instrument was calibrated before each analysis with white and black standard tiles. Parameters $L^{*}$ (lightness, black $=0$, white $=100), a^{*}$ (redness $a^{*}>0$, greenness $a^{*}<0$ ), and $b^{*}$ (yellowness, $b^{*}>0$, blue $b^{*}<0$ ) were quantified on each sample using a $10^{\circ}$ position of the standard observer.

Crust colour was determined on nine pre-selected locations on the crust of each loaf, while crumb colour was determined on three points on the three central slices of each sample.

\section{Statistical analysis}

One-way analysis of variance (ANOVA) and Tukey-LSD post hoc test at a $95 \%$ confidence level were performed to compare the particle size and WBC of the fibres. Two-way ANOVA and Tukey-LSD post hoc test at a $95 \%$ confidence level were performed to evaluate the effects of bread formulation and the level of water addition on physicochemical properties of bread samples at $\alpha=0.05$. The eta squared $\left(\eta^{2}\right)$ was computed according to Eq. (1) to observe the amount of variance explained in the main effects and interactions of the ANOVA models by each measured independent variable 
$\eta^{2}=\frac{\mathrm{SS}_{\mathrm{ef}}}{\mathrm{SS}_{\mathrm{tot}}}$

where $\mathrm{SS}_{\mathrm{ef}}$ is the sums of squares for the considered effect, and $\mathrm{SS}_{\text {tot }}$ is the total sums of squares for all effects, the interaction, and the residual error.

The indicative effect size limits explained by $\eta^{2}$ are $>0.01$ : Small effect size, $>0.06$ : Medium effect size, $>0.14$ : Large effect size [30].

Pearson correlation coefficients $(r)$ were also calculated considering a two-tailed significance level $P<0.05$. Principal component analysis (PCA) was carried out using normalized variables and considering two or three production batches for each sample. All the statistical tests were performed using SPSS statistical software (Version 27.0, SPSS Inc., IL, USA).

\section{Results and discussion}

\section{Analyses on wheat bran and chestnut peels}

Mean dimension of chestnut peels and wheat bran particles, analysed by means of laser diffraction, was equal to $705.7 \pm 51.6$ and $740.2 \pm 64.2 \mu \mathrm{m}$, respectively; no significant differences between the two studied fibres were observed for this parameter.

Water-binding capacity (WBC) of chestnut peels resulted significantly lower compared to wheat bran $(2.42 \pm 0.08$ $\mathrm{g}_{\text {water }} / \mathrm{g}_{\text {dry weight }}$ vs $\left.5.48 \pm 0.59 \mathrm{~g}_{\text {water }} / \mathrm{g}_{\text {dry weight }}, P<0.05\right)$. This result can be related to the significant lower fibre content of chestnut peel $\left(33 \pm 2.1 \%_{\mathrm{dw}}\right)$ in comparison to wheat bran $\left(42.4 \pm 1.0 \%_{\mathrm{dw}}\right)$. The polysaccharide constituents of dietary fibres are indeed strongly hydrophilic. Water is held on the hydrophilic sites of the fibre itself or within void spaces in the molecular structure [31].

\section{Analyses on breads}

\section{Moisture content and water activity}

Moisture content of the crumb resulted significantly affected by the amount of water added to the recipe $\left(\eta^{2}=0.94\right.$, $P<0.001)$. In general, crumb moisture content significantly increased for rising levels of added water, without being significantly affected by the presence of different fibre sources (Table 1).

The moisture content of the crust resulted to be significantly affected by both formulation and water addition $(P<0.05$ and $P<0.001$, respectively); in general, it increased for higher levels of water used in the formulation (Table 1), except for $\mathrm{CP}$ which did not show a clear trend. The control bread $\mathrm{C}$ showed the strongest rise of crust moisture content, in comparison to the other formulations, increasing of $83 \%$ by passing from 54 to $71 \mathrm{~g}$ of added water/ $100 \mathrm{~g}$ flour. By splitting the data as function of the water addition (Table 1), the crust moisture content of the breads at the lowest and highest water addition level (54 $\mathrm{g}$ and $71 \mathrm{~g} / 100 \mathrm{~g}$ flour, respectively) differed significantly among the studied samples $(P<0.05)$. The $\mathrm{C}$ bread showed the lowest moisture content at $54 \mathrm{~g}$ of added water compared to WB and CP; conversely, at $71 \mathrm{~g}$ of added water, $\mathrm{CP}$ revealed the lowest moisture content (Table 1). This different behaviour among the samples is in accordance with

Table 1 Moisture content and water activity of crust and crumb of control bread (C), bread fortified with wheat bran (WB), or chestnut peels (CP) at different levels of water addition

\begin{tabular}{|c|c|c|c|c|c|c|c|c|c|}
\hline \multirow[t]{2}{*}{ Bread type } & \multirow{2}{*}{$\begin{array}{l}\text { Added water } \\
\text { (g/100 g flour) }\end{array}$} & \multicolumn{4}{|c|}{ Moisture content (w/w \%) } & \multicolumn{4}{|l|}{ Water activity } \\
\hline & & Crust & & Crumb & & Crust & & Crumb & \\
\hline \multirow[t]{4}{*}{ C } & 54 & $13.67 \pm 0.37$ & $\mathrm{~b} / \mathrm{C}$ & $37.89 \pm 0.91$ & $\mathrm{c} / \mathrm{A}$ & $0.853 \pm 0.026$ & $\mathrm{~b} / \mathrm{B}$ & $0.973 \pm 0.001$ & $\mathrm{~b} / \mathrm{A}$ \\
\hline & 60 & $14.02 \pm 0.17$ & $\mathrm{~b} / \mathrm{A}$ & $39.62 \pm 0.92$ & $\mathrm{c} / \mathrm{B}$ & $0.823 \pm 0.014$ & $\mathrm{bc} / \mathrm{B}$ & $0.973 \pm 0.001$ & $\mathrm{~b} / \mathrm{A}$ \\
\hline & 66 & $16.56 \pm 1.19$ & $\mathrm{~b} / \mathrm{A}$ & $42.63 \pm 1.82$ & $\mathrm{~b} / \mathrm{A}$ & $0.789 \pm 0.025$ & $\mathrm{c} / \mathrm{A}$ & $0.986 \pm 0.003$ & $\mathrm{a} / \mathrm{A}$ \\
\hline & 71 & $25.13 \pm 6.14$ & $\mathrm{a} / \mathrm{A}$ & $46.77 \pm 1.09$ & $\mathrm{a} / \mathrm{A}$ & $0.951 \pm 0.007$ & $\mathrm{a} / \mathrm{A}$ & $0.987 \pm 0.002$ & $\mathrm{a} / \mathrm{A}$ \\
\hline \multirow[t]{4}{*}{ WB } & 54 & $15.20 \pm 0.45$ & $\mathrm{bc} / \mathrm{B}$ & $36.89 \pm 0.37$ & $\mathrm{c} / \mathrm{A}$ & $0.878 \pm 0.008$ & $\mathrm{a} / \mathrm{AB}$ & $0.973 \pm 0.002$ & $\mathrm{~b} / \mathrm{A}$ \\
\hline & 60 & $14.19 \pm 1.17$ & $\mathrm{c} / \mathrm{A}$ & $42.05 \pm 0.52$ & $\mathrm{~b} / \mathrm{A}$ & $0.837 \pm 0.027$ & $\mathrm{ab} / \mathrm{B}$ & $0.975 \pm 0.002$ & $\mathrm{~b} / \mathrm{A}$ \\
\hline & 66 & $16.99 \pm 1.10$ & $\mathrm{ab} / \mathrm{A}$ & $42.43 \pm 1.34$ & $\mathrm{~b} / \mathrm{A}$ & $0.793 \pm 0.019$ & $\mathrm{~b} / \mathrm{A}$ & $0.987 \pm 0.002$ & $\mathrm{a} / \mathrm{A}$ \\
\hline & 71 & $19.16 \pm 2.66$ & $\mathrm{a} / \mathrm{AB}$ & $45.32 \pm 1.46$ & $\mathrm{a} / \mathrm{A}$ & $0.889 \pm 0.023$ & $\mathrm{a} / \mathrm{B}$ & $0.974 \pm 0.003$ & $\mathrm{~b} / \mathrm{B}$ \\
\hline \multirow[t]{4}{*}{$\mathrm{CP}$} & 54 & $16.29 \pm 0.31$ & $\mathrm{a} / \mathrm{A}$ & $37.46 \pm 0.41$ & $\mathrm{bc} / \mathrm{A}$ & $0.914 \pm 0.021$ & $\mathrm{a} / \mathrm{A}$ & $0.977 \pm 0.003$ & $\mathrm{ab} / \mathrm{A}$ \\
\hline & 60 & $13.12 \pm 0.23$ & $\mathrm{c} / \mathrm{A}$ & $41.52 \pm 0.80$ & $\mathrm{bc} / \mathrm{AB}$ & $0.907 \pm 0.023$ & $\mathrm{ab} / \mathrm{A}$ & $0.969 \pm 0.002$ & $\mathrm{~b} / \mathrm{B}$ \\
\hline & 66 & $16.03 \pm 1.41$ & $\mathrm{ab} / \mathrm{A}$ & $40.86 \pm 3.23$ & $\mathrm{ab} / \mathrm{A}$ & $0.844 \pm 0.033$ & $\mathrm{~b} / \mathrm{A}$ & $0.981 \pm 0.000$ & $\mathrm{a} / \mathrm{B}$ \\
\hline & 71 & $14.52 \pm 0.70$ & $\mathrm{~b} / \mathrm{B}$ & $45.52 \pm 3.40$ & $\mathrm{a} / \mathrm{A}$ & $0.913 \pm 0.017$ & $\mathrm{a} / \mathrm{AB}$ & $0.971 \pm 0.008$ & $\mathrm{ab} / \mathrm{B}$ \\
\hline
\end{tabular}

${ }^{\mathrm{a}-\mathrm{c}}$ Lower case letters indicate a significant difference $(P<0.05)$ within the same bread among different water addition levels

${ }^{\mathrm{A}-\mathrm{C}}$ Upper case letters indicate a significant difference $(P<0.05)$ within the same water addition levels among the different bread samples 
the significant statistical interaction between the two considered main effects $\left(\eta^{2}=0.48, P<0.001\right.$, Table S1). The presence of fibres in WB and CP breads may have helped in reducing the moisture losses during baking, as these components are able to promote the water-holding capacity of the formulation [32], especially when the level of water in the formulation is relatively low (54 $\mathrm{g}$ of added water per $100 \mathrm{~g}$ flour). On the other hand, in the presence of $71 \mathrm{~g}$ of added water per $100 \mathrm{~g}$ of flour, $\mathrm{CP}$ showed the lowest values of crust moisture content, followed by WB and C (Table 1). The lower moisture content of CP in comparison to WB may be due to the lower fibre content of $\mathrm{CP}$ in comparison to WB (Paragraph 3.1) and, consequently, to the lower WBC in presence of high amounts of added water [31].

The crust and crumb water activity values were in line with those observed by other authors on breads enriched with different bran fractions [33]. Both crust and crumb water activity values were mainly affected by the different water addition levels $\left(\eta^{2}=0.67\right.$ and 0.59 , respectively, $P<0.001)$ and less by the formulation effect $\left(\eta^{2}=0.17\right.$ and 0.13 , respectively, $P<0.001$, Table S1). As observed for the moisture content, the $a_{\mathrm{w}}$ values increased in C bread crust and crumb for increasing level of added water (Table 1), while a well-defined trend was not observable in cases of $\mathrm{WB}$ and $\mathrm{CP}$ variants. CP resulted in general the formulation with the higher values of crust $a_{\mathrm{w}}$, probably because the chestnut peels components can physically entrap water without forming chemical bonds. The water activity values of the crumb correlated positively to the crumb moisture content, as expected $(r=0.628 ; \mathrm{P}<0.05)$.

\section{Bread volume and crumb porosity}

Breads volume, measured immediately after baking and cooling, was significantly affected by the formulation $\left(\eta^{2}=0.42, P<0.05\right.$, Table S1). In particular, a significant difference in the bread volume was observed between $\mathrm{C}$ and WB samples, for all the water addition levels, being characterized by a mean volume of $3.5 \pm 0.1$ and $3.3 \pm 0.2 \mathrm{~g} / \mathrm{mL}$, respectively. A reduced volume development with the addition of WB was an expectable result, as WB particles may be able to interfere with the formation of the gluten network as they mainly act as a "filler" substance; moreover, also the presence of glutathione and other reducing agents in WB and their related chemical effects on the gluten fraction [34, 35] may be partially responsible for the volume reduction. On the contrary, $\mathrm{CP}$ bread (mean volume of $3.4 \pm 0.3 \mathrm{~g} / \mathrm{mL}$ ) did not show a significant difference with the other two samples $(P>0.05)$, despite being slightly lower than $\mathrm{C}$, probably because of the lower fibre content of $\mathrm{CP}$ in comparison to WB. No significant differences in volume development were linked to the levels of water addition $(P>0.05)$.
The measure of the pores' density (number of pores $/ \mathrm{mm}^{2}$ ) revealed a slight dependence both from the water addition level and the bread formulation (Table 2). The number of pores decreased by increasing the level of added water, mostly for CP; a negative correlation between pore density and crumb moisture content was indeed found $(r=-0.415$, $P<0.05)$. In general, $\mathrm{CP}$ resulted the sample with the higher pore density, followed by WB and C. Similar results were already observed by other authors in gluten-free breads formulated with different levels of water and xanthan gum [21].

The dimensional distribution of pores in bread crumb slices was differently affected by the formulation, the water addition level, and the interaction between these two factors (Table S1). The more represented image pore classes were the first $\left(0.001-0.005 \mathrm{~mm}^{2}\right)$ and the fourth $\left(0.01-1.00 \mathrm{~mm}^{2}\right)$, for all the formulations; in terms of relative frequency, they represented, respectively, the $34.9 \pm 8.8 \%$ and $44.4 \pm 9.5 \%$ of the crumb porosity. All the samples showed a quite large and heterogeneous distribution of crumb pores, that has also been reported for commercial breads and attributed to the difficulties to obtain products with standardized characteristics also when a well-established production technology is used [36].

The image analysis results (Table 2) underlined that the two smaller dimensional classes of pores (0.001-0.005 and $0.005-0.008 \mathrm{~mm}^{2}$ ) were more affected by the level of added water $\left(\eta^{2}=0.74\right.$ and $0.54, P<0.001$, respectively, Table S1) rather than by the formulation. In particular, it was possible to observe a decreasing trend of the percentage of pores in the second dimensional class for higher levels of added water. Also, the second dimensional class showed significant negative relation with the moisture content measured in the crumb $(r=-0.39, P<0.05)$; water activity of the crumb was negatively correlated with the first, second, and third dimensional pore classes $(r=-0.65,-0.36,-0.40$, respectively, $P<0.05)$ but positively correlated with the two other classes ( $r=0.66$ and 0.54 , respectively, $P<0.05$ ). The first dimensional class showed a significantly lower percentage of pores at a water addition level of $66 \mathrm{~g} / 100 \mathrm{~g}$ of flour $(P<0.05)$; a similar result was also observed in the case of the third dimensional class $\left(0.008-0.010 \mathrm{~mm}^{2}\right)$. Conversely, the fourth dimensional class $\left(0.010-1.000 \mathrm{~mm}^{2}\right)$, that was mainly influenced by the water addition level $\left(\eta^{2}=0.82\right.$, $P<0.001$ ), determined the opposite result, with the sample at a water addition level of $66 \mathrm{~g} / 100 \mathrm{~g}$ of flour showing the highest value for all the three formulations (Table 2). These results were in line with the results of Upadhyay et al. [37] who observed an increase in the mean size of air bubbles developed in the bread dough at higher water concentrations, at comparable conditions of dough fermentation; as a result, a few bubbles of larger dimensions were formed. The authors stated that this observation may be due to an increase in the surface tension in the cell walls because of 


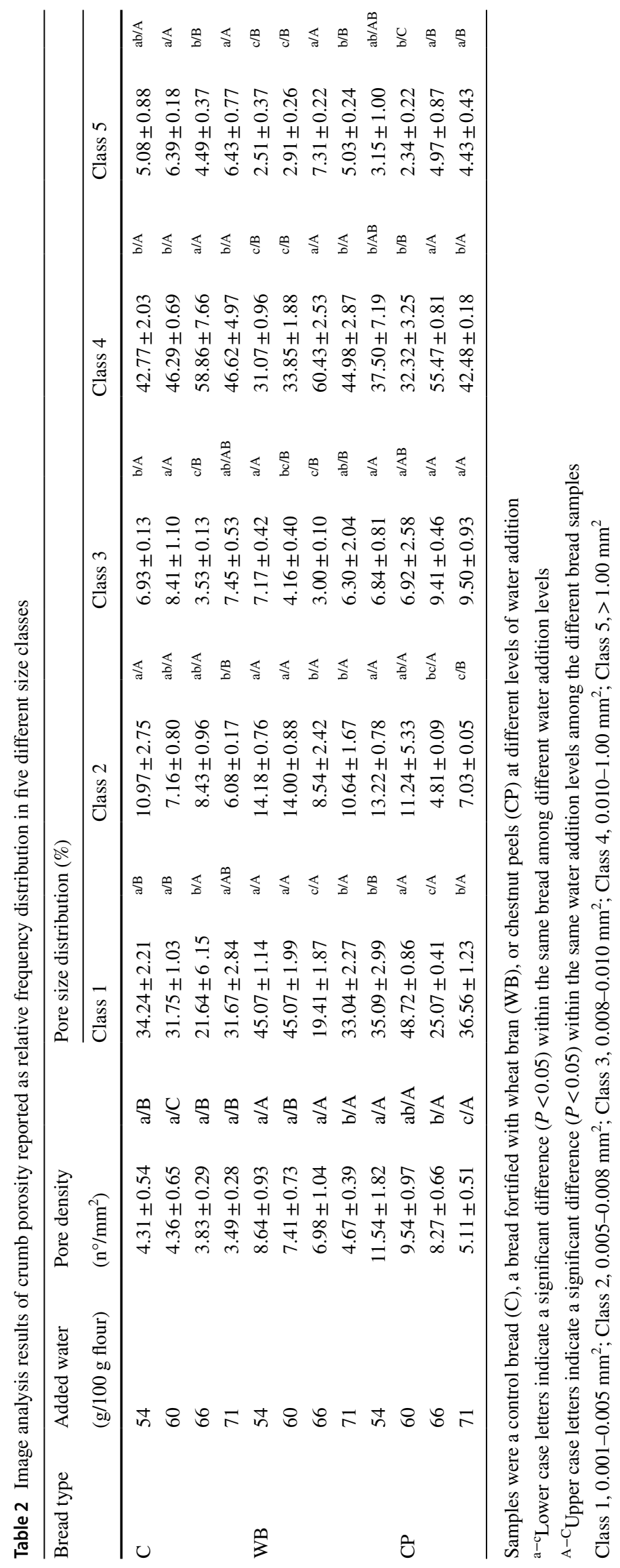


higher water concentrations. Rinaldi et al. [12], observed a higher percentage of pores belonging to the high-dimensional classes in the case of bread formulations having poor volume development as a consequence of high WBC and water-holding capacity (WHC). Larsen and Greenwood [38] reported that crumb grain was negatively scored by a panel group when increasing levels of water were added to the dough, leaving however unaffected loaf volume and bake scores.

A different dimensional distribution of crumb grain pores was also observable for the three different formulations. In particular, $\mathrm{C}$ in comparison with $\mathrm{WB}$ and/or CP variants had a significantly lower frequency percentage for the first dimensional class $\left(0.001-0.005 \mathrm{~mm}^{2}\right)$, for all the water addition levels, except for the formulation with $66 \mathrm{~g}$ of water $100 \mathrm{~g}$ of flour. Conversely, $\mathrm{C}$ showed a significantly higher frequency percentage for the fifth dimensional class $\left(>1.00 \mathrm{~mm}^{2}\right)$ than the two experimental ones, in all the cases except for the water addition level of $66 \mathrm{~g} / 100 \mathrm{~g}$ of flour. A greater relative abundance of pores with dimensions higher than $1.00 \mathrm{~mm}^{2}$ in $\mathrm{C}$ bread may be linked to the greater volume development of the loaf [39], which was confirmed by the statistical comparison between $\mathrm{C}$ and WB volumes, but not between $\mathrm{C}$ and $\mathrm{CP}$ volumes. The higher frequency percentage for the fifth dimensional class $(>1.00$ $\mathrm{mm}^{2}$ ) and the greater volume development observed for $\mathrm{C}$ in comparison to the two experimental breads may be due to the interfering effect of WB and CP during the development of the gluten network. The result is the formation of a less-organized structure that is less able to stabilize the air bubbles that are formed during the breadmaking operations. Also, the fourth dimensional class $\left(0.010-1.000 \mathrm{~mm}^{2}\right)$ generally had higher frequencies values in the $\mathrm{C}$ bread than in WB and CP, despite this difference was found only at lower water addition levels (54 and $60 \mathrm{~g} / 100 \mathrm{~g}$ of flour).

The main effect of formulation $\left(\eta^{2}=0.40, P<0.001\right)$ was predominant on the third dimensional class $(0.009-0.010$ $\mathrm{mm}^{2}$ ). CP showed a significantly higher frequency abundance than C and WB $(8.17 \pm 1.95 \%$, versus $6.70 \pm 1.81 \%$ and $5.35 \pm 1.92 \%$, respectively). Positive correlations have been found between pores' density and the first $(r=0.339$, $P<0.05)$ and second $(r=0.476, P<0.01)$ pore dimensional classes. On the other hand, the fourth and fifth dimensional pore classes showed a negative correlation with the pores' density $(r=-0.427, P<0.05 ;-0.594, P<0.01$, respectively).

\section{Texture analysis}

The results of texture analysis for breads crust and crumb are reported in Table 3. The most relevant factor influencing the crust hardness was the water addition level $\left(\eta^{2}=0.57\right.$, $P<0.001$, Table S1), without a clear trend among the samples (Table 3). It is well known that water exerts a plasticizing role in a food matrix [40] that can be responsible for the reduction of textural hardness of the product. Some differences among samples in terms of crust hardness were also determined by the different formulation, despite a clear trend was not observable.

Concerning crumb hardness, both formulation and water addition levels showed a significant effect $\left(\eta^{2} \sim 0.39-0.40\right.$, $P<0.001$ ). For low levels of added water (54 and $60 \mathrm{~g} / 100 \mathrm{~g}$ flour), crumb hardness was significantly higher in $\mathrm{C}$ than in WB and CP (with the exception of WP and C at $54 \mathrm{~g} / 100 \mathrm{~g}$

Table 3 Textural parameters measured in the crust and in the crumb of different bread formulations

\begin{tabular}{|c|c|c|c|c|c|c|c|c|c|c|c|}
\hline \multirow{3}{*}{$\begin{array}{l}\text { Bread type } \\
\mathrm{C}\end{array}$} & \multirow{3}{*}{$\begin{array}{l}\begin{array}{l}\text { Added water } \\
(\mathrm{g} / 100 \mathrm{~g})\end{array} \\
54\end{array}$} & \multirow{2}{*}{\multicolumn{2}{|c|}{$\frac{\text { Crust }}{\text { Hardness }(N)}$}} & \multicolumn{8}{|l|}{ Crumb } \\
\hline & & & & \multicolumn{2}{|l|}{ Hardness $(N)$} & \multicolumn{2}{|l|}{ Resilience (\%) } & \multicolumn{2}{|c|}{ Cohesiveness (-) } & \multicolumn{2}{|c|}{ Chewiness $(N)$} \\
\hline & & $2.00 \pm 0.42$ & $\mathrm{a} / \mathrm{A}$ & $2.51 \pm 0.50$ & $\mathrm{~b} / \mathrm{A}$ & $39.21 \pm 1.75$ & $\mathrm{c} / \mathrm{A}$ & $0.73 \pm 0.02$ & $\mathrm{~b} / \mathrm{B}$ & $1.76 \pm 0.33$ & $\mathrm{bc} / \mathrm{A}$ \\
\hline & 60 & $1.32 \pm 0.27$ & $\mathrm{~b} / \mathrm{A}$ & $3.11 \pm 0.69$ & $\mathrm{a} / \mathrm{A}$ & $42.64 \pm 1.30$ & $\mathrm{~b} / \mathrm{A}$ & $0.75 \pm 0.02$ & $\mathrm{ab} / \mathrm{A}$ & $2.15 \pm 0.57$ & $\mathrm{ab} / \mathrm{A}$ \\
\hline & 66 & $2.11 \pm 0.44$ & $\mathrm{a} / \mathrm{B}$ & $1.89 \pm 0.45$ & $\mathrm{c} / \mathrm{B}$ & $48.30 \pm 2.03$ & $\mathrm{a} / \mathrm{A}$ & $0.81 \pm 0.01$ & $\mathrm{a} / \mathrm{A}$ & $1.51 \pm 0.34$ & $\mathrm{c} / \mathrm{A}$ \\
\hline & 71 & $1.23 \pm 0.44$ & $\mathrm{~b} / \mathrm{A}$ & $2.59 \pm 0.55$ & $\mathrm{~b} / \mathrm{A}$ & $48.17 \pm 1.76$ & $\mathrm{a} / \mathrm{A}$ & $0.70 \pm 0.14$ & $\mathrm{~b} / \mathrm{A}$ & $2.48 \pm 1.10$ & $\mathrm{a} / \mathrm{A}$ \\
\hline \multirow[t]{4}{*}{ WB } & 54 & $2.10 \pm 0.41$ & $\mathrm{~b} / \mathrm{A}$ & $2.18 \pm 0.47$ & $\mathrm{a} / \mathrm{AB}$ & $40.12 \pm 0.78$ & $\mathrm{c} / \mathrm{A}$ & $0.76 \pm 0.01$ & $\mathrm{a} / \mathrm{A}$ & $1.61 \pm 0.32$ & $\mathrm{a} / \mathrm{AB}$ \\
\hline & 60 & $1.36 \pm 0.34$ & $\mathrm{c} / \mathrm{A}$ & $1.90 \pm 0.48$ & $\mathrm{a} / \mathrm{B}$ & $43.23 \pm 2.19$ & $\mathrm{~b} / \mathrm{A}$ & $0.76 \pm 0.03$ & $\mathrm{a} / \mathrm{A}$ & $1.62 \pm 0.77$ & $\mathrm{a} / \mathrm{B}$ \\
\hline & 66 & $3.39 \pm 0.92$ & $\mathrm{a} / \mathrm{A}$ & $1.28 \pm 0.24$ & $\mathrm{~b} / \mathrm{B}$ & $47.94 \pm 3.35$ & $\mathrm{a} / \mathrm{A}$ & $0.77 \pm 0.10$ & $\mathrm{a} / \mathrm{A}$ & $0.99 \pm 0.24$ & $\mathrm{~b} / \mathrm{B}$ \\
\hline & 71 & $0.93 \pm 0.20$ & $\mathrm{c} / \mathrm{B}$ & $1.87 \pm 0.38$ & $\mathrm{a} / \mathrm{B}$ & $47.01 \pm 2.91$ & $\mathrm{a} / \mathrm{A}$ & $0.77 \pm 0.03$ & $\mathrm{a} / \mathrm{A}$ & $1.60 \pm 0.57$ & $\mathrm{a} / \mathrm{B}$ \\
\hline \multirow[t]{4}{*}{$\mathrm{CP}$} & 54 & $1.20 \pm 0.26$ & $\mathrm{~b} / \mathrm{B}$ & $1.98 \pm 0.45$ & $\mathrm{~b} / \mathrm{B}$ & $37.31 \pm 1.23$ & $\mathrm{c} / \mathrm{B}$ & $0.75 \pm 0.02$ & $\mathrm{a} / \mathrm{AB}$ & $1.43 \pm 0.32$ & $\mathrm{a} / \mathrm{B}$ \\
\hline & 60 & $1.45 \pm 0.47$ & $\mathrm{ab} / \mathrm{A}$ & $1.64 \pm 0.45$ & $\mathrm{bc} / \mathrm{B}$ & $41.90 \pm 1.58$ & $\mathrm{~b} / \mathrm{A}$ & $0.77 \pm 0.02$ & $\mathrm{a} / \mathrm{A}$ & $1.30 \pm 0.42$ & $\mathrm{a} / \mathrm{B}$ \\
\hline & 66 & $1.51 \pm 0.28$ & $\mathrm{a} / \mathrm{C}$ & $1.42 \pm 0.42$ & $\mathrm{c} / \mathrm{A}$ & $47.09 \pm 1.50$ & $\mathrm{a} / \mathrm{A}$ & $0.79 \pm 0.05$ & $\mathrm{a} / \mathrm{A}$ & $1.13 \pm 0.35$ & $\mathrm{a} / \mathrm{B}$ \\
\hline & 71 & $0.85 \pm 0.18$ & $\mathrm{c} / \mathrm{B}$ & $2.52 \pm 0.58$ & $\mathrm{a} / \mathrm{A}$ & $47.58 \pm 3.44$ & $\mathrm{a} / \mathrm{A}$ & $0.75 \pm 0.21$ & $\mathrm{a} / \mathrm{A}$ & $1.37 \pm 0.73$ & $\mathrm{a} / \mathrm{B}$ \\
\hline
\end{tabular}

Samples were a control bread (C), a bread fortified with wheat bran (WB), or chestnut peels (CP) at different levels of water addition

${ }^{a-c}$ Lower case letters indicate a significant difference $(P<0.05)$ within the same bread among different water addition levels

${ }^{\mathrm{A}-\mathrm{C}}$ Upper case letters indicate a significant difference $(P<0.05)$ within the same water addition levels among the different bread samples 
flour that were not significantly different), while in the samples with more added water (66 and $71 \mathrm{~g} / 100 \mathrm{~g}$ flour), $\mathrm{CP}$ showed a similar or even harder crumb texture, compared to the other bread formulations. This behaviour can be explained by the ability of fibres to compete with wheat flour components to bind and organize water molecules in the product [41, 42], and then to reduce viscous dissipation effects; at the same time, fibres in presence of low water contents may reduce the textural hardness of the system, because they may interfere with the formation of a wellorganized gluten/starch structure [43]. The differences in terms of textural hardness may also be linked to the different crumb grain development: in particular, crumb hardness correlated positively to the relative abundance of class the third pore class $(r=0.448, P<0.05)$.

The variation of chewiness among the samples was mainly explained by the formulation factor $\left(\eta^{2}=0.53\right.$, $P<0.001)$ rather than by the water addition levels $\left(\eta^{2}=0.32\right.$, $P<0.001)$. The level of chewiness increased with the addition of fibres in bread recipes (independently from its source). This result is in accordance with previous studies regarding the addition of different sources of dietary fibres in bread formulations $[44,45]$; as chewiness is related to the energy required to chew a food product until it can be swallowed, it can be stated that the addition of CP and WP fibres may be responsible for the rise of the structural rigidity of the bread system.

The other considered textural crumb attributes (resilience and cohesiveness) were mainly affected by the water addition levels $\left(\eta^{2}=0.97, P<0.001\right.$ and $\eta^{2}=0.56, P<0.05$, respectively) and less by formulation (Table $\mathrm{S} 1$ ). In general, resilience raised for increasing level of water regardless of the presence or absence of fibres; a negative correlation has also been found between resilience and pore density $(r=-0.527, P<0.05)$. Resilience is a textural parameter that describe the ability of a food structure subjected to a strain to counteract against the deformation and to regain its original height; a rise of resilience at increasing levels of water content has also been observed in the case of glutenfree breads [46].

Cohesiveness was only subjected to slight variation in $\mathrm{C}$ bread as a function of the different levels of added water, while it remained constant in WB and CP.

\section{Colour}

Colorimetric observations are reported in Table 4. Concerning colour indicators, formulation influenced the evolution of lightness and redness $\left(L^{*}\right.$ and $\left.+a^{*}\right)\left(\eta^{2}=0.85\right.$ and 0.91 , $P<0.001$, Table S1), while yellowness $\left(+b^{*}\right)$ was in similar extent affected by both formulation and water addition level $\left(\eta^{2}=0.42\right.$ and $\left.0.45, P<0.001\right)$. The addition of both the fibre variants significantly decreased the lightness of bread crumb; conversely, it significantly increased the redness parameter $a^{*}(P<0.05)$, as a direct consequence of the presence of coloured fibres that modify the crumb appearance [47]. In particular, by considering the mean data of the different levels of added water, CP showed the lowest value of $L^{*}$ (59.6 \pm 4.8 , while WB showed only a slight, but significant difference of lightness if compared to $C(68.33 \pm 3.57$ and $72.60 \pm 3.73)$. Considering redness, $\mathrm{CP}$ showed the highest value of $a^{*}(4.53 \pm 1.40)$, followed by WB $(2.01 \pm 0.53)$ and
Table 4 Colorimetric parameters $\left(L^{*}, a^{*}, b^{*}\right)$ measured in the crumb of different bread formulations

\begin{tabular}{llrlllll}
\hline Bread type & $\begin{array}{l}\text { Added water } \\
(\mathrm{g} / 100 \mathrm{~g})\end{array}$ & Lightness $L^{*}$ & & Redness $a^{*}$ & & Yellowness $b^{*}$ \\
& & & & & & \\
\hline $\mathrm{C}$ & 54 & $70.97 \pm 3.94$ & $\mathrm{~b} / \mathrm{A}$ & $0.30 \pm 0.07$ & $\mathrm{bc} / \mathrm{C}$ & $13.79 \pm 1.40$ & $\mathrm{~b} / \mathrm{A}$ \\
& 60 & $71.55 \pm 2.06$ & $\mathrm{~b} / \mathrm{A}$ & $0.43 \pm 0.10$ & $\mathrm{a} / \mathrm{C}$ & $13.97 \pm 1.66$ & $\mathrm{~b} / \mathrm{A}$ \\
& 66 & $76.31 \pm 4.00$ & $\mathrm{a} / \mathrm{A}$ & $0.17 \pm 0.08$ & $\mathrm{~b} / \mathrm{C}$ & $16.22 \pm 1.51$ & $\mathrm{a} / \mathrm{B}$ \\
& 71 & $72.33 \pm 2.76$ & $\mathrm{~b} / \mathrm{A}$ & $0.30 \pm 0.15$ & $\mathrm{ab} / \mathrm{C}$ & $13.47 \pm 0.86$ & $\mathrm{~b} / \mathrm{A}$ \\
$\mathrm{WB}$ & 54 & $68.50 \pm 2.57$ & $\mathrm{~b} / \mathrm{A}$ & $2.11 \pm 0.43$ & $\mathrm{ab} / \mathrm{B}$ & $13.53 \pm 1.24$ & $\mathrm{ab} / \mathrm{A}$ \\
& 60 & $69.43 \pm 2.95$ & $\mathrm{ab} / \mathrm{A}$ & $1.82 \pm 0.48$ & $\mathrm{~b} / \mathrm{B}$ & $13.49 \pm 1.17$ & $\mathrm{~b} / \mathrm{A}$ \\
& 66 & $71.33 \pm 2.30$ & $\mathrm{a} / \mathrm{B}$ & $2.46 \pm 0.45$ & $\mathrm{a} / \mathrm{B}$ & $18.45 \pm 0.83$ & $\mathrm{a} / \mathrm{A}$ \\
& 71 & $64.08 \pm 1.79$ & $\mathrm{c} / \mathrm{B}$ & $1.55 \pm 0.35$ & $\mathrm{c} / \mathrm{B}$ & $11.41 \pm 1.53$ & $\mathrm{c} / \mathrm{B}$ \\
$\mathrm{CP}$ & 54 & $58.61 \pm 3.12$ & $\mathrm{~b} / \mathrm{B}$ & $4.22 \pm 0.33$ & $\mathrm{~b} / \mathrm{A}$ & $9.26 \pm 1.09$ & $\mathrm{c} / \mathrm{B}$ \\
& 60 & $59.50 \pm 2.42$ & $\mathrm{ab} / \mathrm{B}$ & $4.28 \pm 0.36$ & $\mathrm{~b} / \mathrm{A}$ & $9.58 \pm 0.84$ & $\mathrm{c} / \mathrm{B}$ \\
& 66 & $56.4 \pm 3.05$ & $\mathrm{~b} / \mathrm{C}$ & $6.17 \pm 0.45$ & $\mathrm{a} / \mathrm{A}$ & $13.72 \pm 0.61$ & $\mathrm{a} / \mathrm{C}$ \\
& 71 & $62.19 \pm 6.04$ & $\mathrm{a} / \mathrm{B}$ & $3.75 \pm 1.60$ & $\mathrm{~b} / \mathrm{A}$ & $11.36 \pm 2.34$ & $\mathrm{~b} / \mathrm{C}$ \\
\hline
\end{tabular}

Samples were a control bread (C), a bread fortified with wheat bran (WB), or chestnut peels (CP) at different levels of water addition

${ }^{\mathrm{a}-\mathrm{c}}$ Lower case letters indicate a significant difference $(P<0.05)$ within the same bread among different water addition levels

${ }^{\mathrm{A}-\mathrm{C}}$ Upper case letters indicate a significant difference $(P<0.05)$ within the same water addition levels among the different bread samples 
C $(0.31 \pm 0.13)$; all the three studied breads were significantly different in terms of $a^{*}$ values $(P<0.05)$. Also, the water addition level showed some significant differences in the case of $a^{*}$ and $b^{*}$ values, despite no clear trends were identifiable among the samples (Table 4). Finally, the lightness of the crumb was found to be positively correlated to the moisture content of the crumb $(r=0.35, P<0.05)$.

\section{Principal component analysis (PCA)}

Multivariate PCA methodology generated six PCs that explained $80.8 \%$ of variance of the dataset. The first two PCs used for sample visualization (Fig. 1a), explained 29.8\% and $15.8 \%$, respectively, of the total variance.

By considering the formulation effect, it was not possible to observe a clear grouping pattern; $\mathrm{CP}$ breads showed relatively more negative scores on the PC 1 , while the control breads showed more positive scores; WB determined intermediate scores if compared to CP and C. Based on the loading plot (Fig. 1b), CP was differentiated by a higher relative abundance of pores of low dimensions (first and second pore classes), a relatively low water activity of the crumb, and a reddish colour (high $a^{*}$ values). Still, the samples related to the different formulations were quite overlapped.

Considering the water added to the formulations, it was possible to observe some grouping patterns: samples containing $71 \mathrm{~g}$ and $66 \mathrm{~g}$ of added water/100 $\mathrm{g}$ of flour showed positive scores in PC 1 . These two groups of samples were differentiated from the samples with lower amount of added water (with the exception of the two control samples having $60 \mathrm{~g}$ of water $/ 100 \mathrm{~g}$ of flour) because of their higher lightness and yellowness ( $L^{*}$ and $\left.b^{*}\right)$, moisture content of crumb and crust and higher pores' dimension (fourth and fifth pore classes). Based on PC 2, these two groups resulted further differentiated: positive scores in the case of $71 \mathrm{~g}$ of water/100 $\mathrm{g}$ of flour and negative in the case of $66 \mathrm{~g}$ of water/100 $\mathrm{g}$ of flour. By observing the loading plot (Fig. 1b), samples with $71 \mathrm{~g}$ of water/100 $\mathrm{g}$ of flour were discriminated by higher values of crumb moisture content, $a_{\mathrm{w}}$, hardness, chewiness, resilience, and cohesiveness, while of $66 \mathrm{~g}$ of added water $100 \mathrm{~g}$ of flour were mainly differentiated by a higher crust hardness, $b^{*}$ value, $a_{\mathrm{w}}$ of the crumb, and loaf volume.

Finally, the samples with lower amount of water added to the formulation (54 and $60 \mathrm{~g} / 100 \mathrm{~g}$ of flour) were related to high scores of the first and second pore dimensional classes, other than to a redder colour.

\section{Conclusion}

In this study, the supplementation of chestnut peels for breadmaking was evaluated for the first time and compared to both a standard wheat bread and to a bread formulation supplemented with wheat bran. In addition, the breads were produced by modulating the water added to the dough.

The results showed that the incorporation of chestnut peels exerts some influence in the physicochemical characteristics of the product, with some of them (i.e., textural and colorimetric characteristics) being critical in defining the consumer appreciation of a bread. The level of water exerted an influence even higher than the presence of fibres

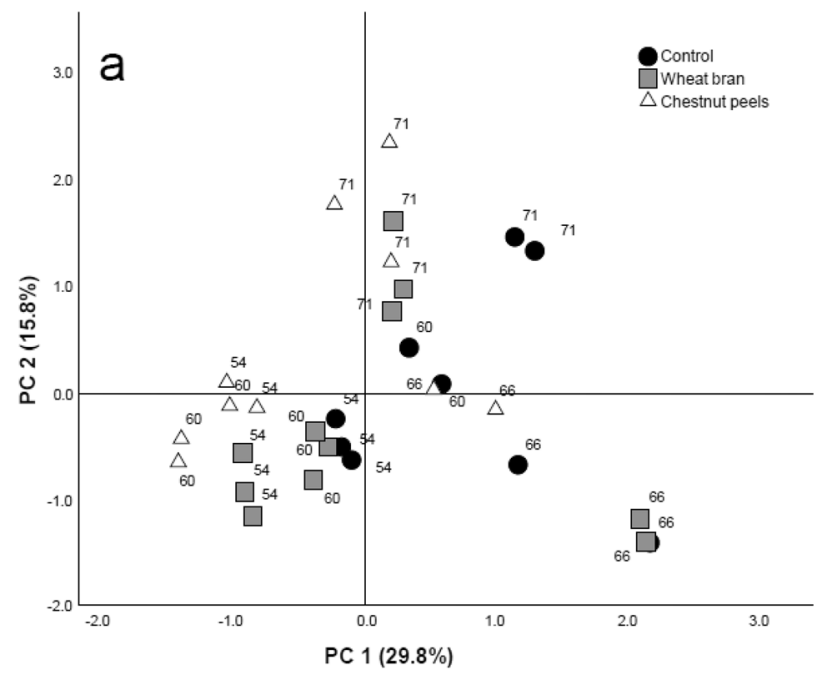

Fig. 1 Principal component analysis (PCA) score (a) and loading (b) plots of the two principal components of the model (PC 1, PC 2). Samples were indicated and labelled according to the formulation (control: $100 \mathrm{~g} / 100 \mathrm{~g}$ standard wheat flour bread; wheat bran:

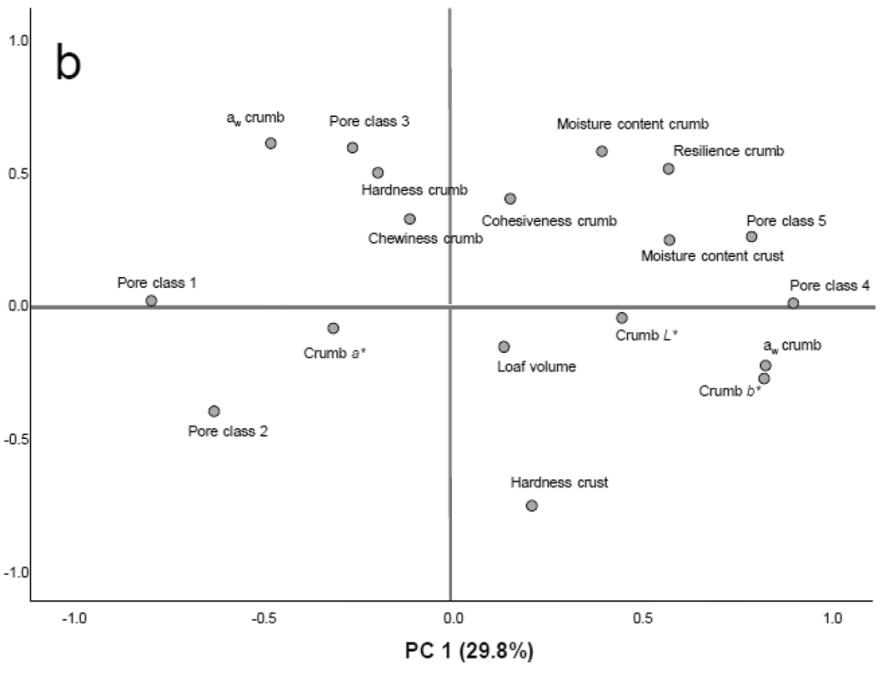

bread supplemented with $3 \mathrm{~g}$ of wheat bran per $100 \mathrm{~g}$ of flour; chestnut peels: bread supplemented with $3 \mathrm{~g}$ of chestnut peels per $100 \mathrm{~g}$ of flour), and water added to the flour $(54,60,66$, and $71 \mathrm{~g} / 100 \mathrm{~g}$ flour) 
on the physicochemical properties of breads, despite a clear trend was not always appreciable. In general, as showed by PCA, the presence of fibres in bread formulations requires higher amount of water to reach characteristic similar to the non-enriched breads.

In view of these results, it can be concluded that the utilization of chestnut peels may be applicable to produce a fibre-enriched product that can contribute to the development of a more sustainable and efficient chestnut supply chain. However, to complete the evaluation of this ingredient, further studies should be carried out to test its effect on doughs with different gluten content, the sensory acceptability, and the potential differences during the shelf life in comparison to the standard and the wheat bran enriched breads, commonly accepted as controls.

Supplementary Information The online version contains supplementary material available at https://doi.org/10.1007/s00217-022-03959-3.

Author contributions The manuscript was written through contributions of all authors. All authors approved the final version of the manuscript.

Funding Italian Ministry of Agriculture (MIPAFF), BIOCAST-La biofunzionalità della filiera del castagno dalla farina agli scarti.

\section{Declarations}

Conflict of interest The authors declare no conflict of interest.

Compliance with ethics requirements Ethical approval was not required for this research.

Open Access This article is licensed under a Creative Commons Attribution 4.0 International License, which permits use, sharing, adaptation, distribution and reproduction in any medium or format, as long as you give appropriate credit to the original author(s) and the source, provide a link to the Creative Commons licence, and indicate if changes were made. The images or other third party material in this article are included in the article's Creative Commons licence, unless indicated otherwise in a credit line to the material. If material is not included in the article's Creative Commons licence and your intended use is not permitted by statutory regulation or exceeds the permitted use, you will need to obtain permission directly from the copyright holder. To view a copy of this licence, visit http://creativecommons.org/licenses/by/4.0/.

\section{References}

1. European Commission (2008) Commission directive No 2008/100/EC on nutrition labelling for foodstuffs as regards recommended daily allowances, energy conversion factors and definitions

2. Delzenne NM, Olivares M, Neyrinck AM, Beaumont M, Kjølbæk L, Larsen TM, Benítez-Páez A, Romaní-Pérez M, Garcia-Campayo V, Bosscher D, Sanz Y, van der Kamp JW (2020) Nutritional interest of dietary fiber and prebiotics in obesity: lessons from the MyNewGut consortium. Clin Nutr 39:414-424
3. European Commission (2006) Regulation (EC) No 1924/2006 of the European Parliament and of the Council of 20 December 2006 on nutrition and health claims made on foods. Official Journal of the European Union, 404:9-25

4. Thebaudin JY, Lefebvre AC, Harrington M, Bourgeois CM (1997) Dietary fibres: nutritional and technological interest. Trends Food Sci Technol 8:41-48

5. Sivam AS, Sun-Waterhouse D, Quek SY, Perera CO (2010) Properties of bread dough with added fiber polysaccharides and phenolic antioxidants: a review. J Food Sci 75:163-174

6. Viuda-Martos M, Ruiz-Navajas Y, Fernández-López J, PérezÁlvarez JA (2010) Effect of added citrus fibre and spice essential oils on quality characteristics and shelf-life of mortadella. Meat Sci 85:568-576

7. Sendra E, Fayos P, Lario Y, Fernández-López J, Sayas-Barberá E, Pérez-Alvarez JA (2008) Incorporation of citrus fibers in fermented milk containing probiotic bacteria. Food Microbiol 25:13-21

8. Vergara-Valencia N, Granados-Pérez E, Agama-Acevedo E, Tovar J, Ruales J, Bello-Pérez LA (2007) Fibre concentrate from mango fruit: Characterization, associated antioxidant capacity and application as a bakery product ingredient. LWT-Food Sci Technol 40:722-729

9. Polaki A, Xasapis P, Fasseas C, Yanniotis S, Mandala I (2010) Fiber and hydrocolloid content affect the microstructural and sensory characteristics of fresh and frozen stored bread. J Food Eng 97:1-7

10. Hemdane S, Jacobs PJ, Dornez E, Verspreet J, Delcour JA, Courtin CM (2016) Wheat (Triticum aestivum L.) bran in bread making: a critical review. Compr Rev Food Sci Food Saf $15: 28-42$

11. Littardi P, Rinaldi M, Grimaldi M, Cavazza A, Chiavaro E (2021) Effect of addition of green coffee parchment on structural, qualitative and chemical properties of gluten-free bread. Foods 10:5

12. Rinaldi M, Littardi P, Paciulli M, Caligiani A, Chiavaro E (2020) Effect of cocoa bean shells granulometries on qualitative properties of gluten-free bread during storage. Eur Food Res Technol 246:1583-1590

13. Bouaziz F, Ben Abdeddayem A, Koubaa M, Ellouz Ghorbel R, Ellouz Chaabouni S (2020) Date seeds as a natural source of dietary fibers to improve texture and sensory properties of wheat bread. Foods 9:737

14. Dalgetty D, Baik BK (2006) Fortification of bread with hulls and cotyledon fibers isolated from peas, lentils, and chickpeas. Cereal Chem 83:269-274

15. De Vasconcelos M, Bennett R, Rosa E, Ferreira-Cardoso J (2010) Composition of European chestnut (Castanea sativa Mill.) and association with health effects: fresh and processed products. J Sci Food Agric 90:1578-1589

16. Barreira JC, Ferreira IC, Oliveira MBP, Pereira JA (2008) Antioxidant activities of the extracts from chestnut flower, leaf, skins and fruit. Food Chem 107:1106-1113

17. Joo SY, Choi HY (2012) Antioxidant activity and quality characteristics of cookies with chestnut inner shell. Korean J Food Nutr 25:224-232

18. Choi YS, Choi JH, Han DJ, Kim HY, Lee MA, Kim HW, Song DH, Lee JW, Kim CJ, Kim CJ (2010) Effects of chestnut (Castanea sativa Mill.) peel powder on quality characteristics of chicken emulsion sausages. Food Sci Anim Resour 30:755-763

19. Sanz-Penella JM, Wronkowska M, Soral-Śmietana M, Collar C, Haros M (2010) Impact of the addition of resistant starch from modified pea starch on dough and bread performance. Eur Food Res Technol 231:499-508

20. Campbell GM, Ross M, Motoi L (2008) Bran in bread: effects of particle size and level of wheat and oat bran on mixing, proving 
and baking. Bubbles in food 2. AACC International Press, pp 337-354

21. Encina-Zelada CR, Cadavez V, Monteiro F, Teixeira JA, Gonzales-Barron U (2018) Combined effect of xanthan gum and water content on physicochemical and textural properties of gluten-free batter and bread. Food Res Int 111:544-555

22. Mastromatteo M, Guida M, Danza A, Laverse J, Frisullo P, Lampignano V, Del Nobile MA (2013) Rheological, microstructural and sensorial properties of durum wheat bread as affected by dough water content. Food Res Int 51:458-466

23. Italian Government Official Bulletin (2001) Regolamento per la revisione della normativa sulla produzione e commercializzazione di sfarinati e paste alimentari. Ital Govt Off Bull 117:6-12

24. Gelati M (2018) Shelf life study of breads with and without gluten enriched with chestnut peels. Master thesis in Food Science and Technology, University of Parma, Italy

25. AOAC International (2007) Official Methods of Analysis of AOAC International, 18th Ed. Method 2009.01

26. Paciulli M, Rinaldi M, Cavazza A, Ganino T, Rodolfi M, Chiancone B, Chiavaro E (2018) Effect of chestnut flour supplementation on physico-chemical properties and oxidative stability of gluten-free biscuits during storage. LWT-Food Sci Technol 98:451-457

27. AOAC Official Method 925.09, 1925, AOAC Official Method 925.09

28. AACC (2000) Method 10-05.01: Guidelines for measurement of volume by rapeseed displacement approved methods of analysis, 11th ed.; AACC International: St. Paul, MN, USA

29. Rinaldi M, Paciulli M, Caligiani A, Scazzina F, Chiavaro E (2017) Sourdough fermentation and chestnut flour in gluten-free bread: a shelf-life evaluation. Food Chem 224:144-152

30. Cohen J (1988) The analysis of variance and covariance. Statistical power analyses for the behavior sciences. Lawrence Erlbaum Associates, Hillsdale, pp 280-288

31. Mudgil D, Barak S (2013) Composition, properties and health benefits of indigestible carbohydrate polymers as dietary fiber: a review. Int J Biol Macromol 61:1-6

32. de Erive MO, Wang T, He F, Chen G (2020) Development of highfiber wheat bread using microfluidized corn bran. Food Chem 310:125921

33. Curti E, Carini E, Bonacini G, Tribuzio G, Vittadini E (2013) Effect of the addition of bran fractions on bread properties. J Cereal Sci 57:325-332

34. Guo L, Xu D, Fang F, Jin Z, Xu X (2020) Effect of glutathione on wheat dough properties and bread quality. J Cereal Sci 96:103116

35. Navrotskyi S, Guo G, Baenziger PS, Xu L, Rose DJ (2019) Impact of wheat bran physical properties and chemical composition on whole grain flour mixing and baking properties. J Cereal Sci 89:102790

36. Angioloni A, Collar C (2009) Bread crumb quality assessment: a plural physical approach. Eur Food Res Technol 229:21-30

37. Upadhyay R, Ghosal D, Mehra A (2012) Characterization of bread dough: Rheological properties and microstructure. J Food Eng 109:104-113

38. Larsen NG, Greenwood DR (1991) Water addition and the physical properties of mechanical dough development doughs and breads. J Cereal Sci 13:195-205

39. Rouillé J, Valle GD, Devaux MF, Marion D, Dubreil L (2005) French bread loaf volume variations and digital image analysis of crumb grain changes induced by the minor components of wheat flour. Cereal Chem 82:20-27

40. Ayala-Soto FE, Serna-Saldívar SO, Welti-Chanes J (2017) Effect of arabinoxylans and laccase on batter rheology and quality of yeast-leavened gluten-free breads. J Cereal Sci 73:10-17

41. Wang CC, Yang Z, Guo XN, Zhu KX (2021) Effects of insoluble dietary fiber and ferulic acid on the quality of steamed bread and gluten aggregation properties. Food Chem 364:130444

42. Wu MY, Shiau SY (2015) Effect of the amount and particle size of pineapple peel fiber on dough rheology and steamed bread quality. J Food Process Preserv 39:549-558

43. Ronda F, Rivero P, Caballero PA, Quilez J (2012) High insoluble fibre content increases in vitro starch digestibility in partially baked breads. Int J Food Sci Nutr 63:971-977

44. Chen Y, Zhao L, He T, Ou Z, Hu Z, Wang K (2019) Effects of mango peel powder on starch digestion and quality characteristics of bread. Int J Biol Macromol 140:647-652

45. Frutos MJ, Guilabert-Antón L, Tomás-Bellido A, HernándezHerrero JA (2008) Effect of artichoke (Cynara scolymus L.) fiber on textural and sensory qualities of wheat bread. Food Sci Technol Int 14:49-55

46. De La Hera E, Rosell CM, Gomez M (2014) Effect of water content and flour particle size on gluten-free bread quality and digestibility. Food Chem 151:526-531

47. Anil M (2007) Using of hazelnut testa as a source of dietary fiber in breadmaking. J Food Eng 80:61-67

Publisher's Note Springer Nature remains neutral with regard to jurisdictional claims in published maps and institutional affiliations. 